\title{
ROMANTICISMO Y LIBERALISMO EN EL PRIMER LASTARRIA
}

\author{
Por \\ BERNARDO SUBERCASEAUX \\ University of Washington
}

La historiografía literaria ha caracterizado a José Victorino Lastarria (1817-1888) como cabeza del romanticismo chileno, a su discurso de la Sociedad Literaria (1842) como el manifiesto romántico de la literatura nacional y a la generación de 1842 como primera generación romántica del país ${ }^{1}$. La relación entre Lastarria y el romanticismo es entonces una cuestión imposible de soslayar; en parte porque pertenece a la tradición crítica y en parte también porque constituye una cuestión no suficientemente aclarada. Debido a que esta relación se inscribe en el tema más amplio del romanticismo en Hispanoamérica (o del romanticismo hispanoamericano) es casi imposible que ella pueda dilucidarse en el curso de un artículo. Lo que sí al menos puede hacerse es mostrar en que sentido la caracterización eurocentrista de Lastarria como romántico es, desde diversos puntos de vista, una caracterización problemática.

Si se toma como parámetro al fenómeno histórico-cultural que tiene su centro de gravitación en el Occidente europeo entre 1789 y 1830 , Lastarria fue, como se ha dicho, impulsor del romanticismo en Chile. Con mayor precisión todavía, puede decirse que estuvo vinculado por su concepción de la literatura como expresión de la sociedad ${ }^{2}$, por su intento de conferirle relevancia filosófica al pensamiento histórico, por el propósito regenerador de sus principios y en fin, porque concibió su obra como factor de edificación política, estuvo vinculado, decíamos, al romanticismo social francés. Esta caracterización, aunque convincente en primera instancia, es susceptible de ser problematizada por lo menos desde tres puntos de vista: el del status del término 'romántico'; el de las diferencias con el fenómeno literario europeo que sirve de parámetro y el del anti-romanticismo explícito del autor.

1 Fernando Alegría, "Orígenes del romanticismo en Chile" (Cuadernos americanos, 5, México, 1947, 173-193); Cedomil Goic, La novela chilena (Santiago: Ed. Universaria, 1968, pp. 17-32).

2 Cedomil Goic, La novela chilena, op. cit., p. 31. 
En sentido amplio el término 'romántico' suele referirse a una cosmovisión total, a una etapa en la historia de la cultura que se manifiesta no sólo en el plano literario sino también en la filosofía, en la historia, en la política, en un estilo intelectual y hasta en un tipo de comportamiento. Es un término, entonces, que encuentra su referente en la producción artística y en la historia de las ideas. En la historiografía literaria europea y norteamericana, partiendo de esta acepción amplia, el concepto ha sido objeto de no pocas discusiones. A.O. Lovejoy en 1924 planteó que en distintos paises las ideas románticas eran heterogéneas y hasta contradictorias, y que por lo tanto no se podía hablar de romanticismo como un movimiento cohesionado, puesto que con ese carácter tal fenómeno no existía ${ }^{3}$. A partir de este planteamiento en las últimas décadas, autores como René Wellek, Northrop Frye y M.H. Abrams han reexaminado el romanticismo, restringiéndolo al fenómeno propiamente literario 4 . Frye, por ejemplo, señala que los escritores trabajan con imágenes y con lenguaje figurado más que con conceptos; dos poetas - dice- pueden estar vinculados entre sí por las imágenes que usan aunque no estén de acuerdo en sus tesis políticas o en sus teorías artísticas. Siendo un término de la historia literaria 'romanticismo' pertenecería entonces al dominio de la historia de las imágenes y no al de la historia de las ideas, en el sentido de conceptos o de tesis 5 . Frente a Lovejoy estos autores proponen una consideración fundamentalmente estética del fenómeno, sostienen que la unidad del romanticismo europeo se da no en la ideología sino en el tipo de imaginación poética de filosófos y creadores de la época.

La crítica, al caracterizar a Lastarria como romántico social, lo ha hecho desde la acepción abarcadora del término, lo que implica suponer que su sustancia romántica estaría constituída por dos formas interdependientes: una de carácter social y otra de carácter literario. La utilización del término "romántico" para la historia de las ideas políticas y filosóficas de Hispanoamérica resulta, sin embargo, problemática; como queda de manifiesto en un libro de Leopoldo Zea, publicado en 1949 (Dos etapas del pensamiento en Hispano-américa). Se trata de un estudio dividido en dos partes, una de las cuales toca el tema del romanticismo y la otra del positivismo. Como lo indica el subtítulo ("Del romanticismo al positivismo") 'romanticismo' está usado aquí para designar una etapa del pensamiento hispanoamericano. En la primera sección Zea hace una sintesis de algunas ideas de Sarmiento, Lastarria, Bilbao y otros

3 A. O. Lovejoy, Essays in the history of ideas, (Baltimore, Maryland, 1948), pp. 228-255. 4 Northrop Frye Ed, Romanticism reconsidered, (New York: Columbia University Press 1963).

5 Northrop Frye, op. cit. , p. VIII. 
pensadores de la primera mitad del siglo XIX. Señala ciertos tópicos comunes como la negación anti-dialéctica del pasado español, la postura adánica, la voluntad de independencia política y cultural, la afinidad, en fin, con las doctrinas de progreso y con el propósito de modernizar la sociedad. Lo que el historiador mexicano llama 'romanticismo' parece, sin embargo, corresponder in strictu sensu a ciertas constantes del liberalismo hispanoamericano en la primera mitad del siglo. Resultaría, en efecto, bastante más adecuado al contenido del libro llamar a esta primera etapa del pensamiento 'liberalismo' y no 'romanticismo' ${ }^{6}$. Salta a la vista, por lo demás, que 'romanticismo' y 'positivismo' son términos que tienen un status teórico diferente.

La incongruencia entre la categoría de 'romanticismo' y aquello a lo cual el autor mexicano la refiere indica que en Hispanoamérica, en el plano ideológico, resulta más apropiado hablar de 'liberalismo' que de 'romanticismo'. Es cierto, como señala Zea, que en lo que tienen de común las concepciones historiográficas y estéticas de Sarmiento, Lastarria, Alberdi, López y Bilbao, ellas pueden filiarse con autores como Michelet, Villemain, Cousin, Victor Hugo, Lamartine y Quinet, todos ellos vinculados al romanticismo europeo. Pero también es cierto que la óptica con que los hispanoamericanos leen y seleccionan esas ideas está condicionada por una visión política y que, en general, lo que vertebra a esa visión son las características y la organicidad del liberalismo criollo.

Otra utilización del vocablo 'romántico', con sentido amplio, es aquella que lo refiere a una postura filosófica común. Mirta Aguirre en El romanticismo de Rousseau a Victor Hugo, dice:

"el romanticismo tradicional consiste en derivar las relaciones entre los hombres arrancando de lo abstracto, de lo imaginario, del hombre por autonomasia, ése que, como bien se ha dicho, no existe en ninguna parte, y en creer que es el factor dominante en la historia de las ideas, ignorando $\rightarrow 0$ queriendo ignorar, porque no siempre el hecho es de buena ley- las situaciones prácticas de convivencia social que prestan sustento a esas ideas."7

La tendencia romántica sería entonces una expresión literaria del idealismo filosófico, una expresión que brotaría de la incompatibilidad entre las exigencias del Yo de ese hombre, concebido en abstracto, y las condiciones de existencia impuestas a ese $Y o$ por la situación real del instante histórico en que vive. De modo general, podría aceptarse que el

$6 \mathrm{Al}$ parecer Zea eludió el subtítulo "Del liberalismo al positivismo"debido a que en ciertos paises el ideario positivista fue un instrumento del liberalismo, y por ende, más que una etapa distinta, una continuidad. Por eludir una confusión cayó, entonces, en otra.

7 Citado por María Poumier (Santiago, Revista de la Universidad de Oriente, 17, marzo, Santiago de Cuba, 1975, p. 193, reseña) 
idealismo es el sustrato filosófico del romanticismo, no es menos cierto, empero, que en gran medida también lo es del liberalismo, especialmente si pensamos en Lastarria y en su perenne dificultad para comprender que los cambios en la conciencia social se van produciendo no por la mayor o menor fuerza de las ideas, sino en virtud de intereses y relaciones sociales. Pero la identificación del romanticismo con un sustrato filosófico corre el peligro de caer en una trampa hegeliana, aquella según la cual se asume que alrededor de 1790 surge en la historia europea una especie de gran tesis que se encarna en el movimiento romántico, supuesto que llevaría a examinar todos los productos culturales del romanticismo como alegorías de esa tesis única ${ }^{8}$.

Resulta por lo tanto problemático caracterizar a Lastarria como romántico en sentido amplio. ¿Puede, por ejemplo, llamarse con entera propiedad romántico a su plan de 1838? ¿No es más bien un plan dieciochesco e iluminista? ¿Puede concebirse a su filosofía de la historia como una proyección de la sensibilidad romántica? ¿No obedece acaso la sustancia social y reformista de Lastarria más que al romanticismo a una idiosincracia liberal y a un conjunto de rasgos específicos del liberalismo criollo?

En su famosa definición del romanticismo Victor Hugo otorga (implícitamente) razón al intento de restringir el término 'romántico a las manifestaciones artísticas, reservando el de 'liberal' para el nivel políticoideológico.

El romanticismo - dice el poeta - tan a menudo mal definido no es en el fondo y ésta es su verdadera definición, más que el liberalismo en la literatura... La libertad en el arte, la libertad en la sociedad; ése es el doble fin a que deben tender por igual los espíritus consecuentes y lógicos. Ya hemos salido de la vieja fórmula social; ¿por qué no hemos de salir también de la vieja fórmula poética.?" 9

¿A qué se debe, pues, esta inclinación nuestra por problematizar la caracterización de 'romántico' cuando ella abarca aspectos ideológicos o extraliterarios? En primer lugar, a que pensamos que ello es metodológicamente necesario para establecer relaciones comprensibles entre el pensamiento filosófico, la ideología política y la literatura. Y en seguida, a que el caso de Lastarria ejemplifica, tal vez mejor que ningún otro, que en Hispanoamérica la concepción utilitaria de la literatura obedece a un programa liberal de emancipación y no a un programa artístico de filiación romántica. Se trata, para decirlo en forma prosaica, de saber donde está la cabeza del proceso y donde la cola y los brazos.

8 Northrop Frye, op. cit. , p. 3.

9 Citado por Roger Picard, El romanticismo social (México: F.C.E., 1947), p. 14. 
Una vez restringida la caracterización de romántico a las concepciones estéticas y a la tendencia artística implícita en la obra - y considerando que el canon tendrá que provenir del parámetro europeo- surgen también algunos aspectos susceptibles de ser problematizados. Aspectos que coinciden con las interrogantes que se hacía Emilio Carilla en su estudio sobre El romanticismo en la América hispana: ¿Romanticismo en Hispanoamérica o romanticismo hispanoamericano? ¿Proyección desteñida de un fenómeno cultural europeo o fenómeno específico con rasgos propios y distintivos? ${ }^{10}$

En relación al romanticismo europeo Lastarria y el llamado romanticismo chileno son fenómenos periféricos tanto en lo geográfico como en lo temporal. Las preferencias del romanticismo social francés empiezan a tener vigencia en Santiago cuando en París están ya en su última etapa. El retardo de las literaturas nacionales hispanoamericanas respecto a las europeas se traduce en acumulación destemporalizada de tradiciones literarias dispares o de autores a veces desplazados de la literatura axial $"$. Lo que es un todo orgánico en Europa, se combina, fragmenta y dispersa en Hispanoamérica.

Por ejemplo, en el Discurso de Lastarria de 1842, están presentes ciertas preferencias de los románticos franceses, pero quien acuda a ese programa con esquemas eurocentristas encontrará, además, rasgos pertinentes a la función que asignaban los neoclásicos a la literatura. Lastarria esgrime allí la idea de que el ideal moral se consigue fundamentalmente con la razón, y que la literatura es en este sentido un medio para hacer la propaganda de la virtud. Llama a estudiar la lengua española en los clásicos y dice que sólo cuando se haya cumplido esta etapa, se estará preparado para recibir la influencia de la literatura francesa. Una y otra vez repite la idea de que el saber es la única solución para la naciente sociedad chilena, y que la literatura está llamada a jugar un papel didáctico. Cuando Fernando Alegría caracteriza el discurso de 1842 como el primer manifiesto romántico de la literatura chilena ${ }^{12}$, resulta necesario, entonces, acotar su carácter racionalista y dieciochesco (en Hispanoamérica, recordemos, no ha habido Revolución Francesa), mostrar en definitiva las diferencias con las ideas matrices de Madame de Stael, Bonald y Victor Hugo, señalar que se trata de un discurso programático en que lo sustantivo es más bien la emancipación o la regeneración de la conciencia y lo adjetivo, la literatura.

10 Emilio Carilla, El romanticismo en la América Hispana, (Madrid, Gredos 1958), p. 40.

11 Cedomil Goic, La novela chilena, op. cit., p. 17.

12 Fernando Alegría, "Orígenes del romanticismo en Chile", op. cit. , p. 190. 
Ahora bien, ¿corresponde esto al parámetro europeo? ¿Es justo caracterizarlo sin más como primer manifiesto romántico? ¿No contribuye acaso una etiqueta de este tipo a ocultar en vez de revelar el fenómeno a que se refiere?

En sus relatos Lastarria configura personajes y utiliza convenciones y motivos caros a la imaginación romántica. Personajes como el proscrito de "El mendigo" (1843), el patriota-rebelde y la amada-suicida de "Rosa" (1848), o como el diablo del Manuscrito (1849); motivos recurrentes como el del amor-imposible, el sentimiento-patriótico o la armonía-de-lanaturaleza. Sin embargo, casi siempre tanto motivos como personajes están mediatizados y carecen de desarrollo ficticio. En "El mendigo" en "Rosa" y en "El alférez Alonso Díaz de Guzmán" (1848) el motivo del amorimposible está al servicio de esquemas argumentales que obedecen a una voluntad de edificación política; lo que significa que no está recreado con morosidad, que no logra crear suspenso, que es siempre elemento externo y nunca llega, como en Europa, a ser pasión. Lo mismo puede decirse de los personajes: prototipos románticos desteñidos, a menudo planos y poco convincentes. En la primera etapa de la obra de Lastarria, hasta 1850 , no hay un sólo personaje del que pueda decirse que el autor se ha volcado emocionalmente en él; únicamente se confiesa en el plano de su vehemencia ideológica, en los esquemas políticos o históricos que sostienen a sus relatos. Se trata, en síntesis, de una literatura de ideas, en que los rasgos de filiación romántica están aprovechados en función civilizadora y liberal.

En 1848 Lastarria editó un pequeño libro con el título de Aguinaldo para 1848, dedicado al bello sexo chileno; especie de almanaque en la tradición de los No me olvides que editaban anualmente los emigrados liberales en Londres. Tal como lo indica el título, la importancia concedida a las mujeres es, qué duda cabe, un elemento romántico, un rasgo que se asienta en la revindicación saint-simoniana de la mujer y en la idea de que ésta era portadora del sentimiento. Lastarria escribió la introducción en verso e incluyó además dos de sus piezas: "Rosa" y "El alférez Alonso Díaz de Guzmán". Los versos introductorios, más que elogiar a la mujer, son casi una chanza sobre el tópico del elogio, y las protagonistas de los relatos aparecen como partes intercambiables de un argumento en donde el ser mujer carece de relevancia. Se trata, entonces, nuevamente, de tópicos mediatizados de preferencias románticas trascendidas por una óptica más bien dieciochesca 13

13 J. V. Lastarria, Recuerdos literarios, p. 250; “nosotros proyectábamos todavía la publicación de un tercer periódico, confiando aun en las aptitudes progresivas de la sociedad; y para sondear la situación, emprendimos hacer una publicación literaria, preparando un pequeño libro con el título de Aguinaldo para 1848, dedicado al bello sexo chileno." 
Antes que Mármol en Argentina y que Manuel Bilbao o Lastarria en Chile, escribieron novelas de tesis Victor Hugo, Alfred de Vigny, George Sand, Eugenio Sue y los escritores que la crítica llama románticos sociales, novelas en que pintaban a la sociedad de la época como materialista y como una sociedad descompuesta por el egoismo ${ }^{14}$. Sin embargo, las novelas de estos autores, aunque en muchos casos son novelas ideológicas concebidas con espíritu de partido, difieren notablemente de los ensayos novelísticos de Lastarria. Son, en primer lugar, obras voluminosas, en que los tópicos románticos están encarados con morosidad, en donde lo ideológico está recubierto por pasiones y suspenso, obras, en fin, que aun siendo novelas sociales revelan una fe en la literatura y en la imaginación, una creencia en la misión profética del escritor.

El romanticismo fue en el viejo continente, como se sabe, un fenómeno multiforme, en el que caben desde un Novalis y un Nerval hasta un Victor Hugo, desde el egotismo y el solipsismo imaginista hasta la filantropía social, desde el desasosiego espiritual de un Byron hasta el utopismo socializante de un Soulié, desde una corriente neoplatónica, ocultista y onírica hasta otra que se vuelca en la emoción social y en la defensa de los ideales de 1789; sin embargo, en toda esta gama del abanico se da un común denominador: la fe (romántica) en la literatura, la conciencia de que el escritor es un visionario, un heraldo que sólo puede ejercer su vocación profética por medio de sus creaciones. Con más énfasis en los románticos alemanes e ingleses, pero también en los franceses, el acto de escribir es concebido como una especie de teodicea secularizada, como una forma de ejercitar el poder redentor de la imaginación. Hay en los románticos europeos la conciencia implícita de que están creando con su literatura una nueva realidad, una realidad que puede estar sentimentalizada, coloreada, mistificada o ideologizada, pero que será siempre una realidad artística, y como tal, una supra-realidad que desafía a la realidad real. Esta perspectiva sienta las bases para la concepción de la literatura como un fin en si misma y como un medio de conocimiento y representación único e insustituible (no es casual que la estética, como disciplina, haya surgido entre los románticos). De ahí a postular la autonomía de la obra poética como una totalidad orgánica y sui generis habrá sólo un paso. A ello se debe, por lo demás, que en las últimas décadas críticos como Franz Kermode y M.H. Abrams hayan hurgado las raíces de la concepción moderna de la literatura en el romanticismo europeo ${ }^{15}$.

Se trata, como se habrá podido notar, de una concepción bien diferente a la de Lastarria, quien durante la primera mitad el siglo tiene una idea

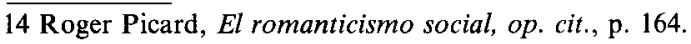

15 M. H. Abrams, Natural supernaturalism (New York: Norton, 1973), pp. 427-428. 
mediatizada de la literatura, en que predomina la fe en las ideas liberales y no la fe en la imaginación, o si se quiere no la fe - al modo de los románticos europeos- en el sacerdocio literario. El mismo Lastarria advierte con lucidez la diferencia entre su concepción y la de los europeos, cuando después del fracaso de 1848 los critica, señalando que habían buscado la libertad en el arte en lugar de promoverla en la realidad.

\begin{abstract}
"En Francia - dice- donde todavía no se sabe lo que es la libertad, había fracasado en 1830 el segundo esfuerzo de la revolución de 1789 para realizar la libertad política, individual y social: una monarquía nueva se había erigido para continuar el mismo sistema de absorción de la monarquía vieja, y fortificarlo por medio de la perfección, de la centralización administrativa, iniciada y planteada por el primer imperio. Los literatos franceses quisieron entonces conquistar para el arte lo que la revolución no había conseguido para el hombre, la posesión de su individualidad, el uso completo de sus derechos, esto es la libertad; y declararon que el arte era un soberano que no dependía sino de sí propio: el Romanticismo era desde entonces lo que el self government en política, proponiéndose alcanzar en el arte por medio de formas nuevas, con toda independencia de las reglas clásicas, ese paladín de la civilización moderna, la libertad, que no atinaban a conseguir en sociedad." 16
\end{abstract}

Fiel a su plan de 1838 , lo fundamental para Lastarria sigue siendo la concepción utilitaria de la literatura en pro de una regeneración liberal de la sociedad ${ }^{17}$. Queda todavía por indagarse si esta concepción mediatizada, tan diferente de la otra, tiene o no, en relación a Chile e Hispanoamérica, un carácter representativo. Pareciera que sí, que en Hispanoamérica - con excepciones como Heredia- sólo puede hablarse de fe romántica en la literatura hacia fines de siglo, con las preferencias modernistas y con Rubén Darío.

Otro aspecto que permite problematizar la caracterización de Lastarria como romántico es que éste ni en su discurso de 1842 ni en ninguna otra ocasión de su vida se manifestó en favor de esa escuela, y más aún, con frecuencia tuvo una actitud crítica respecto a lo que él entendía por romanticismo. Como Sarmiento, López y Sanfuentes, creía que la tendencia romántica era ya cosa del pasado, parte de una tradición que

16 J. V. Lastarria, Miscelánea histórica y literaria (Valparaíso: La Patria, 1970), t. I p. 5.

17 Enrique Anderson Imbert, Historia de la literatura hispano-americana, (México, F.C.E. 1966), señala que el romanticismo criollo fue una obra civilizadora más que una escuela de Bellas Letras. 
debía ser superada ${ }^{18}$. Identificaba al romanticismo con la Edad Media, con el sentimiento, con la evocación, con el esplín y hasta con la actitud lunática. "Una hora perdida", artículo de costumbres de 1842, y uno de los primeros escritos del publicista, se inicia con una divagación satírica sobre la moda romántica:

" 'Hay ciertas horas sin hora' ha dicho en letra de molde un poeta de estos tiempos, y sabe Dios lo que pretendió decir: ya se ve, no es dado muchas veces al miserable vulgo, a esa parte preciosa de la humanidad a que por su solidez le dicen masas, el comprender los altos conceptos que allá en sus lucubraciones estampa en el papel un poeta que delira o un pensador de los de ogaño, que tanto gustan de encumbrarse hasta perderse de vista. Ya que ahora está la moda por los enigmas, yo también me digo: 'Hay ciertas horas perdidas', y a la verdad que tampoco entiendo lo que quisiera decir; es tan fácil esto de decir lo que no se piensa y de pensar lo que no se puede expresar...". 19

Guía su ironía una sensibilidad claramente contraria a la exhibición del Yo, y a ciertas divagaciones meláncolicas o enigmáticas caras al romanticismo byroniano. Estos aspectos corresponden, además, a la poesía que delira y que repite en distintos tonos el "yo te amo", género que será un blanco recurrente en la postura anti-romántica de Lastarria y de los hermanos Blest Gana.

"Como el único premio de los escritores baladíes es el que ellos se procuran hablando de vez en cuando con suave modestia de sus talentos y de otras cosillas que les atañen, yo no quiero ser menos, y diré algo de mi propio. Hay un cierto desabrimiento que asalta a veces el corazón y se pega en el con tenaz afición, que no se halla medio de arrancarlo. Desabrimiento es éste que algunos consideran como un signo, como una prueba de la inmortalidad de nuestro espíritu, y dicen que es un requerimiento de pago que Dios nos hace con más benignidad que la de nuestra ley de procedimientos. Otros menos timoratos lo caracterizan como exceso de vida, como una superabundancia de nuestro ser, que es necesario no desperdiciar... Más no estoy para filosofias; lo que no se puede negar es que el tal ataque nervioso causa amarguras en el alma y hace que lo miremos todo, sino con maligna indiferencia, con aquel odio estúpido que tanto asemeja al hombre con las fieras. Entonces viene aquello de maldecir de la sociedad, de conocer y admirar la falacia del sexo amable, aquello de renegar de la indolencia de los que mandan y de la mala fe de todos: entonces se nos presenta la humanidad

18 D. F. Sarmiento, El Mercurio, 1842, "El romanticismo era pues una verdadera insurrección literaria como las políticas que le han precedido. Pero no construyó nada tampoco y desapareció el día que concluyó su tarea, ¿Quién le ha sucedido en el lugar que dejó desamparado? ¿Quién aspira al menos a sucederle? El socialismo, perdónennos la palabra: el socialismo, es decir la necesidad de hacer conducir la ciencia el arte y la política al único fin de mejorar la suerte de los pueblos, de favorecer las tendencias liberales, de combatir las preocupaciones retrógradas."

19 J. V. Lastarria, Miscelánea histórica y literaria, op. cit. III, p. 7. 
con sus deformidades y con sus llagas incurables; ya no es el hombre el rey de la creación; y el que es más necio traga un veneno o se manda guardar una onza de plomo en las concavidades del cráneo, y el que no, se echa a su cama o sale a pasearse, Dios mediante." 20

La ironía apunta tanto a las costumbres como al movimiento literario: al romanticismo confesional y al romanticismo del yo rebelde frente al mundo, del tedium vitae ${ }^{21}$ y del culto resentido de la soledad.

Siguiendo a Bello, Lastarria también ve en la escuela romántica el peligro de que la libertad literaria se convierta en licencia y en uso descuidado de la lengua. Pero la postura anti-romántica que tendrá mayor peso (especialmente después de 1848) será aquella que acusa al romanticismo de ser una escuela extranjera, y que en consecuencia señala que la literatura que se oriente según sus cánones no podrá llegar jamás a ser expresión orgánica de la sociedad en que se origina. Lastarria y Joaquín Blest Gana dicen, al respecto:

“el espíritu de imitación de la escuela romántica (es el) menos adecuado a nuestras costumbres, (el) menos conciliable con el interés primordial de la literatura del nuevo continente. Estudien en buena hora nuestros poetas y escritores las formas y el estilo de otras literaturas, pero es ridículo, nada natural y sobre todo pernicioso, el prurito de imitarlas también en el fondo que representa un estado social completamente diverso del nuestro". 22

$20 \mathrm{~J}$. V. Lastarria, Miscelánea histórica y literaria, op. cit. t III, p. 8-9.

$21 \mathrm{Ya}$ en 1827 aparece en El patriota chileno, un artículo titulado "El Esplin", divulgando la moda romántica: "Esta es una enfermedad --dice-cuya causa no es aun bien conocida. Los doctores Dubois, Dupreyten y Broussais, que han tratado de la curación de varios jóvenes, naturales de las orillas del Tamesis, han visto frustrarse su saber delante de esta enfermedad inglesa. ¿Este mal existe en la cabeza? ¿Tiene su asiento en el corazón? Casi estamos inclinados a creer que mora en esta parte del cuerpo humano. Hay gentes que pretenden que es un exceso de sensibilidad, y casi estamos tentados a creer lo mismo; pero sólo cuando esta enfermedad procede del amor. En este caso los síntomas son fáciles de conocerse. El enfermo se haya triste, inquieto y taciturno; no duerme nunca pero está siempre amodorrado; suspira, desea, anhela la felicidad, la busca por todas partes; la encuentra al cabo, se apodera de ella, más sólo se encuentra con una sombra. El desgraciado, cansado de la vida... acaba por matarse con un veneno o asfixiándose. El esplín procede también del odio... La perversidad de la especie humana y la infedilidad de una mujer causaron el esplín del Lord Byron: una alma como la suya debía sentir con vehemencia los golpes de la suerte. Como él mismo lo dice, no hizo más que soñar la dicha. La desgracia se apoderó de él desde la cuna, y le arrastró a la tumba. Qué hombre fue éste Lod Byron!", El patriota chileno, 19, 20 enero 1827, 3, p. 82. 22 J. V. Lastarria y Joaquín Blest Gana, "Informe crítico sobre la obra de los Sres. Amunátegui", Revista del Pacífico, Valparaíso, 1860, t. III, pp. 32-33. 
Esta postura anti-romántica obedece, como es sabido, a una concepción que toma cuerpo con el romanticismo europeo, y que proclama que la literatura debe ser expresión orgánica de la sociedad en que se gesta. He aquí una paradoja frecuente en los literatos liberales del siglo XIX: el haberse propuesto desarrollar una literatura propia, teniendo que partir, obligadamente, de una tradición literaria ajena. O para decirlo de otra manera: el haber sido consumidores no europeos (sin Revolución Francesa y sin Desarrollo Industrial) de una cultura europea.

Bajo esta contradicción late, empero, otra más profunda y decisiva. El sector ilustrado y liberal, con el que se identifica Lastarria, quiso imponer -al menos durante la primera mitad del siglo- una modernización regida por un modelo ideológico-cultural francés, por un modelo a medias real y a medias ideal. Se trataba, en última instancia, de una modernización que no respondía al grado de desarrollo social de Chile, y que al ser injertada en un sustrato en que prevalecían determinantes tradicionales ${ }^{23}$ resultaba, en el mejor de los casos jacobinismo en el aire, ideas aisladas o flotantes, y en el peor, mera y ramplona cosmetología ${ }^{24}$.

El Lastarria de la década del 40 anhela, como Victor Hugo, una literatura progresista, moderna, una suerte de épica de la República; pero tal literatura no parece viable en una sociedad en que a despecho del liberalismo teórico la hegemonía de la gran propiedad agraria se ha reforzado y engrandecido 25 , y en que los asomos de burguesía nacional van cediendo a esa hegemonía, limitando la fuente y la clientela de una posible épica republicana. La formación de una tradición literaria moderna (o burgesa), entre 1810 y 1850 , sólo era viable en el plano del "deber ser", pero no como expresión orgánica de la sociedad. Lo que sí fue en cierta medida una expresión congruente con el desfase ocurrido en esa etapa, es que una literatura que quiso ser épica de la República, como la del primer Lastarria (1840 a 1850), no haya podido llegar a ser más que una literatura ideologizante, árida y voluntarista.

Este desfase entre las condiciones reales de la vida social y la ideología de la "modernización", es, como ya hemos señalado, uno de los factores que condiciona el carácter abstracto y con frecuencia idealista del liberalismo lastarriano; a su vez, desde esta intransigencia liberal surge el

23 Enzo Faletto y Julieta Kirkwood, Sociedad burguesa y liberalismo romántico en el siglo $X I X$, (Santiago, Chile, 1974. Mimeografiado) Agustín Cueva, El desarrollo del capitalismo en América Latina (México: Siglo XXI, 1977), son, entre otros, autores que se refieren a esta supervivencia de relaciones agrarias precapitalistas durante el siglo XIX.

24 Jotabeche, burlándose de este tipo de barniz, escribe (en 1842): “Sabes saludar en francés?... Il suffit. Tu es fierement romantique".

25 Agustín Cueva, op. cit. p. 17. 
criterio con que el publicista escoge o rechaza aspectos de la tradición europea y el modo en que los utiliza. A partir de estos desfases y confluencias se genera, entonces, un fenómeno cultural que está vinculado a la tradición romántica pero que a la vez es distinto de ella. Para comprender la singularidad de Lastarria y evitar las generalizaciones que lo presentan como un simple epifenómeno de la cultura europea, conviene, por lo tanto, estudiarlo primero como un 'liberal' y luego como un 'romántico', como un 'liberal' cuya ideología evoluciona y tiene apellidos. Por otra parte, restringiendo el romanticismo al plano estético, conviene hablar, no del promotor de ese movimiento en Chile, sino, simplemente, de influencias o de elementos románticos; haciéndose necesario, además, relacionar esos elementos románticos con su idiosincracia liberal (que los determina y trasciende) y con la totalidad histórico-social en que esa idiosincracia está inserta 26.

26 Las diferencias regionales que se observan en la literatura hispanoamericana del siglo XIX, pueden ser comprendidas analizando la evolución del liberalismo en cada una de las regiones. Véase Alejandro Losada, "La literatura como praxis social en América Latina, Ideologies and Literature, Minnesota, 1977, 4, pp. 33-62. 